\title{
EFEITOS IMEDIATOS E LATENTES DE TRATAMENTOS TÉRMICO E QUÍMICO EM SEMENTES DE BRACHIARIA BRIZANTHA CULTIVAR MARANDU ${ }^{(1)}$
}

\author{
LEILA MARTINS $^{(2)}$; WALTER RODRIGUES DA SILVA ${ }^{(3,4)}$
}

\begin{abstract}
RESUMO
O objetivo da pesquisa foi o de estudar os efeitos, particularmente sobre a dormência, de tratamentos térmico e químico em sementes de Brachiaria brizantha cv. Marandu. Sementes, com taxas de dormência superiores a $25 \%$ e pureza física acima de $98 \%$, foram submetidas às temperaturas de 65,70 , 75 e $80{ }^{\circ} \mathrm{C}$ durante 5,10 e 15 horas e à imersão em $\mathrm{H}_{2} \mathrm{SO}_{4}(98 \%, 36 \mathrm{~N})$ por 15 minutos. No início e no fim do armazenamento de seis meses, realizado em ambiente não controlado de laboratório, as sementes foram avaliadas por meio dos testes de germinação, de tetrazólio (viabilidade), de primeira contagem de germinação, de comprimento da parte aérea das plântulas, de emergência das plântulas e de índice de velocidade de emergência. Tratamentos térmicos específicos equiparam-se ao de $\mathrm{H}_{2} \mathrm{SO}_{4}$ ao reduzir a taxa de dormência das sementes sem provocar deterioração fisiológica latente; a aplicação de $70^{\circ} \mathrm{C}$ por 15 horas destaca-se positivamente em relação à de $\mathrm{H}_{2} \mathrm{O}_{4}$ e aos demais tratamentos térmicos.
\end{abstract}

Palavras-chave: armazenagem de sementes, longevidade de sementes, ácido sulfúrico, dormência de sementes.

\section{ABSTRACT \\ IMMEDIATE AND LATENT EFFECTS OF THERMAL AND CHEMICAL TREATMENTS ON SEEDS OF BRACHIARIA BRIZANTHA CV. MARANDU}

The objective of this research was to study the effects of thermal and chemical treatments on Brachiaria brizantha $\mathrm{cv}$. Marandu seeds, particularly in relation to dormancy. Seeds presenting dormancy indices higher than $25 \%$ and physical purity above $98 \%$ were submitted to temperatures of $65,70,75$ and $80{ }^{\circ} \mathrm{C}$ for periods of 5,10 and 15 hours and to immersion in sulphuric acid $(98 \%, 36 \mathrm{~N})$ for 15 minutes. At the beginning and at the end of six months storage under uncontrolled laboratory conditions, seeds were evaluated in relation to germination, tetrazolium (viability), first count of germination, seedling shoot lenght, seedling emergence and speed of emergence index. Some specific thermal treatments showed positive effects similar to sulphuric acid treatment in reducing seed dormancy without causing latent physiological deterioration; $70^{\circ} \mathrm{C} / 15 \mathrm{~h}$ was the best thermal treatment to dormancy reduction in cv. Marandu.

Key words: seed storage, vigor, sulfuric acid, seed dormancy.

$\left({ }^{1}\right)$ Financiado pela Fundação de Amparo à Pesquisa do Estado de São Paulo (FAPESP). Recebido para publicação em 18 de julho de 2002 e aceito em 31 de janeiro de 2003.

$\left({ }^{2}\right)$ Laboratório Central de Sementes e Mudas (DSMM-CATI). Caixa Postal 1291, 13073-001 Campinas (SP), Brasil. E mail: leila@cati.sp.gov.br

$\left({ }^{3}\right)$ Departamento de Produção Vegetal, ESALQ/USP, 13418-900 Piracicaba (SP), Brasil. E-mail: wrsilva@carpa.ciagri.usp.br

$\left({ }^{4}\right)$ Com bolsa de produtividade científica do CNPq. 


\section{INTRODUÇÃO}

A produção de sementes de Brachiaria brizantha apresenta, além de desuniformidade na maturação e degrana, dormência nas sementes cuja natureza, intensidade e persistência não estão suficientemente esclarecidas. Esse fenômeno fisiológico dificulta o estabelecimento uniforme das populações e, paralelamente, favorece o surgimento de plantas invasoras na pastagem. O estudo de alternativas, para a superação da dormência, pode ser útil na avaliação da qualidade fisiológica em laboratório e, principalmente, contribuir para o desenvolvimento de métodos que, utilizáveis em larga escala, permitam a comercialização de sementes com dormência parcial ou totalmente eliminada.

Entende-se como dormência o estado fisiológico em que uma semente viável não germina quando colocada em condições de ambiente admitidas como adequadas (ROBERTS, 1972); esse mesmo autor atribuiu a dormência das sementes de gramíneas forrageiras, principalmente, à presença de substâncias fixadoras de oxigênio nas estruturas de cobertura. BeWLeY e BLACK (1978) consideraram que os hormônios promotores da germinação, particularmente as giberelinas e citocininas, interagiriam com os inibidores para que a germinação ocorresse. KHAN (1970) propôs a existência de um balanço promotor-inibidor em que a relação quantitativa de substâncias reguladoras determinaria o controle da dormência; destacou, adicionalmente, que a lema e a pálea seriam estruturas responsáveis pela imposição da dormência nas sementes de gramíneas.

Embora as Regras para Análise de Sementes (BRASIL, 1992) recomendem a utilização de escarificação com ácido sulfúrico concentrado nas sementes de Brachiaria, MACEDO et al. (1994) concluíram que o efeito do tratamento, em Brachiaria humidicola, é prejudicial à germinação. Por outro lado, Garcia e Cícero (1992) e Martins e Lago (1996) constataram que a aplicação do método foi efetiva para superar a dormência em sementes de Brachiaria brizantha cv. Marandu. Contudo, na imersão das sementes em ácido sulfúrico, devem ser consideradas as inconveniências relacionadas à segurança do trabalhador envolvido na aplicação e, em adição, à preservação do meio ambiente com o descarte dos resíduos provenientes da operação.

Uma possibilidade promissora, que tem sido estudada nas pesquisas direcionadas à superação da dormência, é a utilização de tratamentos térmicos empregando temperaturas admitidas como potencialmente prejudiciais à qualidade fisiológica das sementes. Almeida (2002), estudando os efeitos da exposição de sementes de Brachiaria dictyoneura cv. Llanero a $85^{\circ} \mathrm{C}$ por 10 e 15 horas, concluiu que o uso do calor constitui-se em alternativa para a redução da dormência. Da mesma forma, aplicações de $80^{\circ} \mathrm{C}$ por 10 horas (MARTins et al., 1997) e de 70 e $85{ }^{\circ} \mathrm{C}$ por 5 , 10 e 15 horas em sementes de Brachiaria brizantha cv. Marandu (MARTINs e SILVA, 2001), conduziram à diminuição da taxa de dormência.

Mesmo considerando resultados positivos, alcançados em estudos sobre a remoção da dormência em sementes de Brachiaria por meio da ação de temperaturas elevadas, permanecem dúvidas relacionadas à quantificação do calor necessário, nas diferentes espécies, para o desenvolvimento de técnicas eficientes.

Assim, o objetivo deste trabalho foi o de estudar os efeitos, particularmente sobre a dormência, de tratamentos térmico e químico em sementes de Brachiaria brizantha cv. Marandu.

\section{MATERIAL E MÉTODOS}

Foram utilizadas amostras de três lotes de sementes de Brachiaria brizantha $\mathrm{cv}$. Marandu, com taxas de dormência superiores a $25 \%$. Os lotes, durante o beneficiamento, passaram por quebrador de torrões, pré-limpeza, coluna de ventilação e mesa gravitacional.

As amostras de cada lote, anteriormente à aplicação dos tratamentos, passaram por limpeza adicional, por meio de peneiras e assoprador pneumático, complementada por separação manual para eliminação de material inerte e de sementes mal formadas; em seguida, contando com pureza física superior a 98\% (BRASIL, 1992), as amostras foram homogeneizadas e divididas em quatro repetições.

Após a aplicação dos tratamentos (Quadro 1), avaliou-se o teor de água conforme o prescrito em BRASIL (1992).

Foram considerados os valores das testemunhas como padrões para a uniformização do teor de água entre os tratamentos; quando necessária, foi feita reidratação das sementes, definida quantitativamente por cálculos, após o tratamento térmico e anteriormente ao início das avaliações fisiológicas realizadas durante o período de armazenamento.

No início e após seis meses de armazenamento, foram feitas as seguintes avaliações:

a) Teor de água: determinado utilizando-se o método da estufa a $105 \pm 3^{\circ} \mathrm{C}$ por 24 horas (BRASIL, 1992). Os dados foram calculados em porcentagem com base na massa úmida (bu). 
Quadro 1. Denominação e descrição dos tratamentos aplicados nos lotes de sementes de Brachiaria brizantha cv Marandu

\begin{tabular}{|c|c|}
\hline Denominação & Descrição \\
\hline Testemunha & Sem tratamento \\
\hline $65^{\circ} \mathrm{C} / 5$ horas & Exposição a $65^{\circ} \mathrm{C}$, durante 5 horas, em estufa \\
\hline $65^{\circ} \mathrm{C} / 10$ horas & Exposição a $65^{\circ} \mathrm{C}$, durante 10 horas, em estufa \\
\hline $65^{\circ} \mathrm{C} / 15$ horas & Exposição a $65^{\circ} \mathrm{C}$, durante 15 horas, em estufa \\
\hline $70^{\circ} \mathrm{C} / 5$ horas & Exposição a $70^{\circ} \mathrm{C}$, durante 5 horas, em estufa \\
\hline $70{ }^{\circ} \mathrm{C} / 10$ horas & Exposição a $70^{\circ} \mathrm{C}$, durante 10 horas, em estufa \\
\hline $70{ }^{\circ} \mathrm{C} / 15$ horas & Exposição a $70^{\circ} \mathrm{C}$, durante 15 horas, em estufa \\
\hline $75^{\circ} \mathrm{C} / 5$ horas & Exposição a $75^{\circ} \mathrm{C}$, durante 5 horas, em estufa \\
\hline $75^{\circ} \mathrm{C} / 10$ horas & Exposição a $75^{\circ} \mathrm{C}$, durante 10 horas, em estufa \\
\hline $75^{\circ} \mathrm{C} / 15$ horas & Exposição a $75^{\circ} \mathrm{C}$, durante 15 horas, em estufa \\
\hline $80^{\circ} \mathrm{C} / 5$ horas & Exposição a $80^{\circ} \mathrm{C}$, durante 5 horas, em estufa \\
\hline $80{ }^{\circ} \mathrm{C} / 10$ horas & Exposição a $80^{\circ} \mathrm{C}$, durante 10 horas, em estufa \\
\hline $80^{\circ} \mathrm{C} / 15$ horas & Exposição a $80^{\circ} \mathrm{C}$, durante 15 horas, em estufa \\
\hline $\mathrm{H}_{2} \mathrm{SO}_{4}$ & $\begin{array}{l}\text { Imersão em ácido sulfúrico }(98 \%, 36 \mathrm{~N}) \text {, durante } 15 \text { minutos, seguida por } \\
\text { lavagem em água corrente e secagem à sombra }\end{array}$ \\
\hline
\end{tabular}

b) Germinação: foi realizada com 50 sementes por repetição. As sementes foram colocadas sobre papel mata-borrão, umedecido com quantidade de água equivalente a 2,5 vezes o seu peso, dentro de caixas plásticas transparentes mantidas em germinador sob temperatura alternada $\left(20^{\circ} \mathrm{C}\right.$ por16 horas no escuro e $35^{\circ} \mathrm{C}$ por 8 horas sob luz); as contagens foram feitas aos 7, 14 e 21 dias após a semeadura. Calcularam-se as porcentagens de plântulas normais e de plântulas anormais. No fim do período, as sementes não germinadas foram submetidas ao teste de tetrazólio para a identificação das sementes dormentes e mortas.

c) Tetrazólio (viabilidade): as sementes remanescentes da avaliação de germinação foram cortadas, bilateral (em relação à largura da semente) e longitudinalmente, e uma das metades colocada em solução aquosa de 2, 3, 5 trifenil cloreto de tetrazólio $(0,075 \%)$ a $40{ }^{\circ} \mathrm{C}$ por quatro horas. Após o descarte da solução e a lavagem em água, as sementes foram identificadas como viáveis (dormentes) ou mortas (Delouche at al., 1962). As taxas (\%) de dormência e de mortalidade foram calculadas em relação à população total participante do teste de germinação.

d) Primeira contagem de germinação: realizado considerando a porcentagem de plântulas normais (BRASIL, 1992), presentes no sétimo dia após a semeadura, na avaliação de germinação das sementes.

e) Comprimento da parte aérea das plântulas: no fim do teste de emergência das plântulas, avaliouse o comprimento $(\mathrm{cm})$ da parte aérea (colo-ápice) das plântulas presentes o qual, somado e dividido pelo número de sementes instaladas, representou o comprimento médio da população. f) Emergência das plântulas: foram empregadas repetições de 50 sementes. Cada repetição foi semeada à profundidade de $0,5 \mathrm{~cm}$, em caixas plásticas transparentes, utilizando substrato de areia lavada umedecido com água destilada. O teste foi realizado em condições ambientais do laboratório e, após 14 dias da semeadura, foi avaliada a porcentagem de plântulas emersas.

g) Índice de Velocidade de Emergência (I.V.E.): calculou-se a partir de valores obtidos durante a realização do teste de emergência das plântulas. Para tanto, foram contadas as plântulas emersas entre o $5 .^{\circ}$ e o $14 .^{\circ}$ dia após a instalação do teste. $\mathrm{O}$ cálculo foi realizado de acordo com a seguinte equação (MAGUIRE, 1962):

$$
I V E=\sum_{i=1}^{n} N i / D i
$$

em que:

$\mathrm{Ni}=$ número de plântulas emersas no dia.

$D i=$ iésimo dia após semeadura.

$n=$ número total de dias do teste.

$i=$ índice de variação.

O delineamento experimental empregado foi o de blocos ao acaso, com quatro repetições por bloco (lote), e as comparações entre médias foram realizadas pelo teste de Tukey a $5 \%$ de probabilidade dentro de cada período de armazenamento. Os dados obtidos foram avaliados pelo programa de análise estatística para microcomputadores - SANEST (ZontA et al., 1984). 
Os dados do teor de água não foram analisados estatisticamente. Paralelamente, os tratamentos foram classificados segundo critério de pontuação (CAliari e Silva, 2001) resultante do somatório do número de tratamentos superados, em valor absoluto, nos testes de germinação (sementes dormentes, plântulas normais, plântulas anormais, sementes mortas) e vigor (primeira contagem do teste de germinação, comprimento da parte aérea da plântula, índice de velocidade de emergência e emergência).

\section{RESULTADOS E DISCUSSÃO}

Os dados do teor de água das sementes (Quadro 2) indicam que a desidratação, promovida com a aplicação dos tratamentos térmicos, foi adequadamente revertida pela reidratação adotada. Esse procedimento permitiu que as sementes tratadas fossem submetidas às avaliações fisiológicas sem interferências provenientes de variações nos seus teores de água. Da mesma forma, as mudanças havidas no grau de umidade das sementes, durante o período de conservação, foram similares entre os tratamentos e, portanto, indicaram uniformidade nas trocas de água com o ambiente, em toda a extensão do local de armazenamento.

A análise dos dados (Quadro 3) destacou que todos os tratamentos aplicados foram eficientes para proporcionar, com significado estatístico, reduções imediatas na taxa de dormência em relação à testemunha. Considerando os tratamentos térmicos, observou-se tendência de redução da dormência com o aumento do tempo de exposição ao calor em todas as temperaturas. Porém, após seis meses de armazenamento (Quadro 4), o uso de $\mathrm{H}_{2} \mathrm{SO}_{4}$ mostrouse estatisticamente inferior à testemunha.

A ação imediata de tratamentos térmicos, na redução da taxa de dormência, foi constatada em sementes de Brachiaria brizantha (MARTINs e SILVA, 2001 e Martins e Lago, 1996), Panicum maximum (Martins e Silva, 1998) e Brachiaria dictyoneura cv. Llanero (Almeida e Silva, 2001); no entanto, HopKinson et al. (1988) relataram que a dormência das sementes de capim-colchão (Paspalum plicatulum) pareceu não ser afetada pela forma de secagem (tempo e temperatura) das sementes.

Paralelamente, o uso de $\mathrm{H}_{2} \mathrm{SO}_{4}$ tem sido eficiente na superação da taxa de dormência em sementes de Panicum maximum (Sмith, 1979; Harty et al., 1983 e Martins e Silva, 1998), de Paspalum notatum (Maeda et al., 1997), de Brachiaria brizantha (GARCIA e Cícero, 1992; Lago e Martins, 1998; Martins e Silva, 2001) e de Brachiaria dyctioneura cv. Llanero (Almeida e Silva, 2001).
No quadro 3 verifica-se que houve acréscimos imediatos significativos, excetuando as aplicações de $65{ }^{\circ} \mathrm{C}$ por 5 horas e 10 horas e de $70{ }^{\circ} \mathrm{C}$ por 5 horas, na taxa de plântulas normais em relação à testemunha com a exposição ao calor. Resultados favoráveis à germinação, decorrentes da exposição das sementes a $85{ }^{\circ} \mathrm{C}$ por 15 horas foram verificados em Brachiaria brizantha (MARTINs e SILva, 2001) e em Brachiaria dictyoneura cv. Llanero (AlmeIDA e SILVA, 2001).

A aplicação de $\mathrm{H}_{2} \mathrm{SO}_{4}$ aumentou significativamente, de modo similar ao verificado nos tratamentos térmicos, a germinação nas comparações com a testemunha. Acréscimos na germinação, pela imersão no ácido foram constatados por MCLEAN e GROF (1968) em Brachiaria ruziziensis e por Oliveira e Mastrocola (1984) em Brachiaria decumbens.

A análise do quadro 4 não mostrou diferença estatisticamente significativa entre os tratamentos em relação à testemunha e, dessa forma, não indicando prejuízos fisiológicos latentes ocorridos de suas aplicações.

Assim, a interpretação conjunta dos dados das taxas de dormência e de plântulas normais indicou que os tratamentos empregados foram eficientes na redução da taxa de dormência e não promoveram prejuízos à viabilidade no fim do período de armazenamento.

Os valores das taxas de plântulas anormais e de sementes mortas não permitiram evidenciar ação imediata diferencial entre os tratamentos e a testemunha (Quadro 3). Resultados similares foram observados após 6 meses de conservação (Quadro 4).

Em relação à taxa de mortalidade, constatações semelhantes foram feitas por MAEDA et al. (1997) ao observarem que as sementes de grama-batatais (Paspalum notatum) não sofreram danos fisiológicos ao serem submetidas a $60^{\circ} \mathrm{C}$. MARTins e Silva (2001), similarmente, verificaram que sementes de Brachiaria brizantha $\mathrm{cv}$. Marandu podem ser submetidas a $70^{\circ} \mathrm{C}$ sem perda de viabilidade.

Dessa maneira, examinando o efeito dos tratamentos sobre as taxas de plântulas anormais e de mortalidade (Quadros 3 e 4), há indicações de que os tratamentos aplicados foram capazes de reduzir a dormência, favorecer a germinação e não representar situações de estresse, promotoras de diminuição na qualidade fisiológica.

No entanto, constatações de prejuízos latentes promovidos por tratamentos térmicos foram relatadas por MARTINS e SILVA (1998) em sementes de capim colonião (Panicum maximum) e MARTINS e SiLva (2001) em sementes de Brachiaria brizantha cv. Marandu. 
Quadro 3. Brachiaria brizantha cv Marandu: dados médios obtidos nos testes de germinação (G), $1 .{ }^{a}$ contagem da germinação (1. $\left.{ }^{a} \mathrm{C}\right)$, comprimento da parte aérea das plântulas (CPA), índice de velocidade de emergência (IVE) e emergência das plântulas (E) sem o armazenamento (efeitos imediatos)

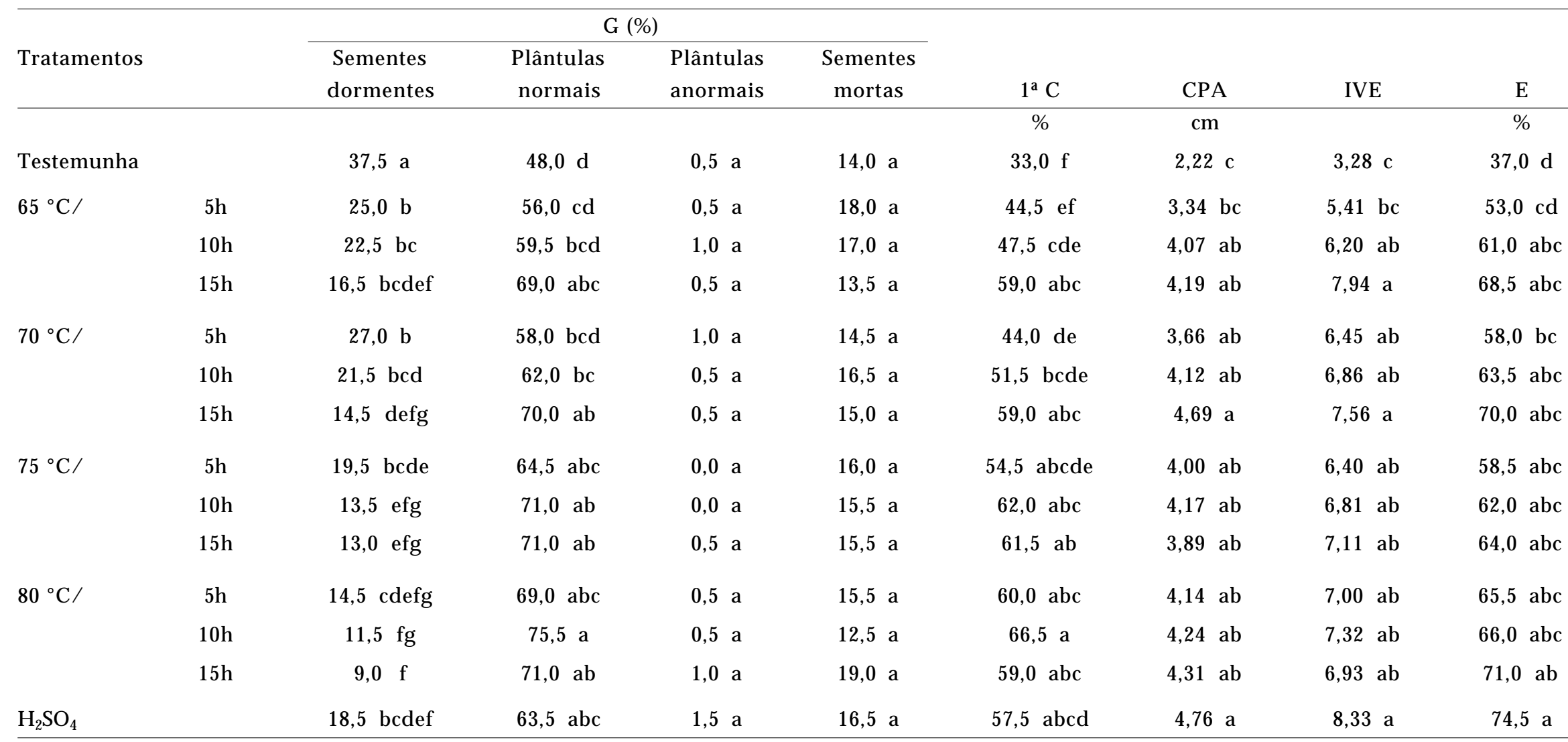

Médias seguidas de mesma letra, na coluna, não diferem estatisticamente, entre si, pelo teste de Tukey $(\mathrm{P}>0,05)$. 
Quadro 4. Brachiaria brizantha cv. Marandu: dados médios obtidos nos testes de germinação (G), 1 . $^{\mathrm{a}}$ contagem da germinação (1. $\left.{ }^{\mathrm{a}} \mathrm{C}\right)$, comprimento da parte aérea das plântulas (CPA), índice de velocidade de emergência (IVE) e emergência das plântulas (E) após armazenamento de 6 meses (efeitos latentes)

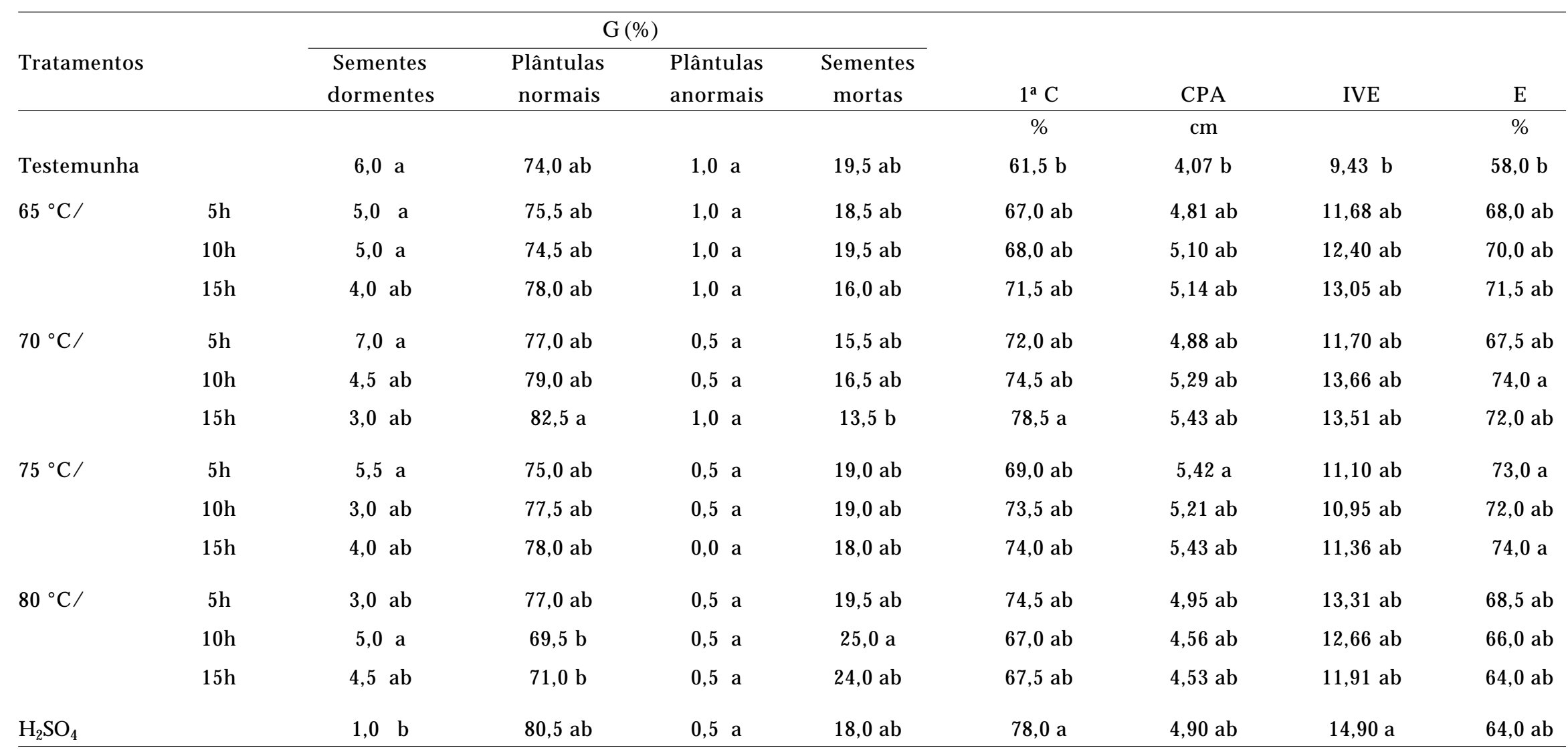


As avaliações de primeira contagem da germinação, comprimento da parte aérea das plântulas, índice de velocidade de emergência e emergência de plântulas (Quadro 3), voltadas às estimativas do vigor, indicaram, excetuando o caso de $65{ }^{\circ} \mathrm{C}$ por 5 horas, efeitos imediatos positivos dos tratamentos aplicados nas comparações com a testemunha. Verificações semelhantes foram feitas por MARTINS e SILVA (2001) em estudo sobre dormência em sementes de Brachiaria brizantha cv. Marandu.

Em relação aos tratamentos térmicos, similarmente ao observado na avaliação de plântulas normais, foi observada tendência, na maioria dos casos, de aumento dos valores obtidos com a ampliação do tempo de exposição ao calor.

Após o armazenamento (Quadro 4), todos os tratamentos aplicados apresentaram-se superiores à testemunha em valores absolutos muito embora, estatisticamente, as diferenças nem sempre tenham sido significativas. Dessa maneira, não foram constatados quaisquer prejuízos fisiológicos latentes gerados pelos tratamentos.

A análise estatística dos dados obtidos, apesar de esclarecer devidamente o comportamento dos tratamentos em relação à testemunha, não possibilitou comparações efetivas de desempenho entre os tratamentos; tal ocorrência, oriunda de variações inerentes aos atributos fisiológicos medidos em cada teste de vigor (Grabe, 1976 e Marcos Filho et al., 1987), é freqüente nos estudos realizados em sementes.

Dessa forma, buscando uma alternativa para a comparação entre tratamentos submetidos a testes de vigor, aplicou-se o critério de classificação por pontuação (CALIARI e SILVA, 2001) considerando os valores absolutos obtidos pelos tratamentos nos diferentes testes.

A classificação obtida (Quadro 5), com base no somatório do número de tratamentos superados em cada teste, permitiu verificar que o tratamento de 80 ${ }^{\circ} \mathrm{C}$ por 10 horas, apesar de apresentar-se superior aos demais anteriormente ao armazenamento, recebeu a última classificação, entre os tratamentos aplicados, após o armazenamento.

Em contrapartida, o tratamento de $70{ }^{\circ} \mathrm{C}$ por 15 horas manteve estabilidade ao obter a segunda (anteriormente ao armazenamento) e primeira (após o armazenamento) classificações na comparação com os demais tratamentos.

Quadro 5. Pontuação geral dos tratamentos nos testes de germinação e de vigor anteriormente ao armazenamento (efeitos imediatos) e após o armazenamento de seis meses (efeitos latentes)

\begin{tabular}{|c|c|c|c|c|}
\hline \multirow{2}{*}{ Classificação } & \multicolumn{2}{|c|}{ Efeitos imediatos } & \multicolumn{2}{|c|}{ Efeitos latentes } \\
\hline & Tratamento & Pontuação & Tratamento & Pontuação \\
\hline $1 .^{\circ}$ & $80^{\circ} \mathrm{C} / 10 \mathrm{~h}$ & 85 & $70{ }^{\circ} \mathrm{C} / 15 \mathrm{~h}$ & 84 \\
\hline $2 .^{\circ}$ & $70{ }^{\circ} \mathrm{C} / 15 \mathrm{~h}$ & 75 & $70{ }^{\circ} \mathrm{C} / 10 \mathrm{~h}$ & 80 \\
\hline $3 .^{\circ}$ & $65^{\circ} \mathrm{C} / 15 \mathrm{~h}$ & 72 & $75^{\circ} \mathrm{C} / 15 \mathrm{~h}$ & 78 \\
\hline $4 .^{\circ}$ & $75^{\circ} \mathrm{C} / 10 \mathrm{~h}$ & 71 & $\mathrm{H}_{2} \mathrm{SO}_{4}$ & 75 \\
\hline $5 .^{\circ}$ & $80^{\circ} \mathrm{C} / 15 \mathrm{~h}$ & 68 & $65^{\circ} \mathrm{C} / 15 \mathrm{~h}$ & 61 \\
\hline $6 .^{\circ}$ & $75^{\circ} \mathrm{C} / 15 \mathrm{~h}$ & 64 & $80^{\circ} \mathrm{C} / 5 \mathrm{~h}$ & 60 \\
\hline $7 .^{\circ}$ & $80^{\circ} \mathrm{C} / 5 \mathrm{~h} ; \mathrm{H}_{2} \mathrm{SO}_{4}$ & 61 & $75^{\circ} \mathrm{C} / 10 \mathrm{~h}$ & 59 \\
\hline $8 .^{\circ}$ & $75^{\circ} \mathrm{C} / 5 \mathrm{~h}$ & 45 & $75^{\circ} \mathrm{C} / 5 \mathrm{~h}$ & 50 \\
\hline $9 .^{\circ}$ & $70{ }^{\circ} \mathrm{C} / 10 \mathrm{~h}$ & 39 & $70{ }^{\circ} \mathrm{C} / 5 \mathrm{~h}$ & 49 \\
\hline $10 .^{\circ}$ & $65^{\circ} \mathrm{C} / 5 \mathrm{~h}$ & 26 & $65^{\circ} \mathrm{C} / 10 \mathrm{~h}$ & 35 \\
\hline $11 .^{\circ}$ & $70{ }^{\circ} \mathrm{C} / 5 \mathrm{~h}$ & 25 & $65^{\circ} \mathrm{C} / 10 \mathrm{~h} ; 80^{\circ} \mathrm{C} / 15 \mathrm{~h}$ & 28 \\
\hline $12 .^{\circ}$ & $65^{\circ} \mathrm{C} / 10 \mathrm{~h}$ & 24 & $80{ }^{\circ} \mathrm{C} / 10 \mathrm{~h}$ & 25 \\
\hline $13^{\underline{0}}$ & Testemunha & 17 & Testemunha & 7 \\
\hline
\end{tabular}




\section{CONCLUSÕES}

1. Tratamentos térmicos específicos equiparam-se ao de $\mathrm{H}_{2} \mathrm{SO}_{4}$ ao reduzir a taxa de dormência das sementes sem provocar deterioração fisiológica latente;

2. A aplicação de $70{ }^{\circ} \mathrm{C}$ por 15 horas destaca-se positivamente em relação à de $\mathrm{H}_{2} \mathrm{SO}_{4}$ e aos demais tratamentos térmicos.

\section{REFERÊNCIAS BIBLIOGRÁFICAS}

ALMEIDA, C.R.; SILVA, W.R. Comportamento da dormência em sementes de braquiária submetidas às ações de tratamentos térmico e químico. Informativo ABRATES, Brasília, v.11, n.2, p.25, 2001.

ALMEIDA, C.R. Comportamento da dormência de sementes de Brachiaria dictyoneura cv. Llanero submetidas às ações do calor e do ácido sulfúrico. 2002. 36f. Tese (Mestrado) - Escola Superior de Agricultura "Luiz de Queiroz", Universidade de São Paulo, Piracicaba.

BEWLEY, J.D.; BLACK, M. Physiology and biochemistry of seeds in relation to germination: viability, dormancy and environmental control. Berlin: Springer-Verlag, 1978. v.2, 375p.

BRASIL. Ministério da Agricultura e Reforma Agrária. Regras para Análise de Sementes. Brasília:SNDA/DNFV/CLV, 1992.365p.

CALIARI, M.F.; SILVA, W.R. Interpretação de dados de testes de vigor na avaliação da qualidade fisiológica de sementes de milho. Revista Brasileira de Sementes, Brasília, v.23, n.1, p.239251, 2001.

DELOUCHE, J.C.; STILL, T.W.; RASPET, M.; LIENHARD, M. The tetrazolium test for seed viability. Mississipi: Mississipi Agricultural Experiment Station, 1962.63p. (Technical Bulletin, .51

GARCIA, J.; CÍCERO, S.M. Superação da dormência em sementes de Brachiaria brizantha cv. Marandu. Scientia Agricola, Piracicaba, v.49, n.1, p.9-13, 1992.

GRABE, D.F. Measurement of seed vigor. Journal of Seed Technology, Beltsville, v.1, n.2, p.18-31, 1976.

HARTY, R.L.; HOPKINSON, J.M.; ENGLISH, B.H. ; ALDER, J. Germination, dormancy and longevity in stored seed of Panicum maximum. Seed Science \& Technology, Zurich, v.11, p.341-351, 1983.

HOPKINSON, J.M.; ENGLISH, B.H. ; HARTY, R.L. Effects of different drying patterns on quality of seed of some tropical pasture grasses. Seed Science E Technology, Zurich, v.16, n.2, p.361-369, 1988.

KHAN, A. A. ABA and kinetin induced changes in cell homogenates, chromatin: bound RNA polymerase and RNA composition. In: CARR, D.J. (Ed.). Plant growth substances. New York: Springer-Verlag, 1970. p.207-215.
LAGO, A.A.; MARTINS, L. Qualidade fisiológica de sementes de Brachiaria brizantha. Pesquisa Agropecuária Brasileira, Brasília, v.33, n.2, p.199-204, 1998.

MACEDO, E.C.; GROTH, D.; LAGO, A.A. Efeito de escarificação com ácido sulfúrico na germinação de sementes de Brachiaria humidicola (RENDLE) SCHWEICK. Pesquisa Agropecuária Brasileira, Brasília, v.29, n.3, p.455-460, 1994.

MAEDA, J.A.; PEREIRA, M.F.D.A.; MEDINA, P.F. Conservação e superação da dormência de sementes de Paspalum notatum Flugge. Revista Brasileira de Sementes, Brasília, v.19, n.2, p.165171, 1997.

MAGUIRE, J.D. Speed of germination: aid in selection and evaluation for seedling emergence and vigor. Crop Science, Madison, v.2, n.2, p.176-177, 1962.

MARCOS FILHO, J.; CÍCERO, S.M.; SILVA, W.R. Avaliação da qualidade das sementes. Piracicaba: FEALQ, 1987. 230p.

MARTINS, L.;SILVA, W.R.; LOT, R.C.; MALAVOLTA, V.M. Tratamentos térmicos e superação da dormência em sementes de Brachiaria brizantha. Informativo Abrates, Brasília, v.7, n.1/2, p.245, 1997.

MARTINS, C.; SILVA, W.R. Superação da dormência de sementes de capim-colonião. Planta Daninha, Botucatu, v.16, n.2, p.77$84,1998$.

MARTINS, L.; LAGO, A.A. Germinação e viabilidade de sementes de Brachiaria brizantha (Hochst. Ex A. Rich.) durante o armazenamento. Revista Brasileira de Sementes, Brasília, v.18, n.2, p.262-266, 1996.

MARTINS, L.; SILVA, W.R. Comportamento da dormência em sementes de braquiária submetidas a tratamentos térmicos e químicos. Pesquisa Agropecuária Brasileira, Brasília, v.36, n.7, p.9971003, 2001.

McLEAN, D.; GROF, B. Effect of seed treatments on Brachiaria mutica and Brachiaria ruziziensis. Queenslaand Journal of Agricultural and Animal Husbandry, Brisbane, v.25, n.1-2, p.81-83, 1968.

OLIVEIRA, P.R.P.; MASTROCOLA, M. A. Brachiaria humidicola (Rendle) Schwickerdt: observações acerca da viabilidade de suas sementes. Boletim da Indústria Animal, Nova Odessa, v.40, n.1, p.49-53, 1984 .

ROBERTS, E.H. Oxidative processes and the control of seed germination. In: HEYDECKER, W. (Ed.). Seed Ecology. University Park: The Pennsylvania State University Press, 1972. p.189-218.

SMITH, R.L. Seed dormancy in Panicum maximum Jacq. Tropical Agriculture, Trinidad, v.56, n.3, p.233-239,1979.

ZONTA, E.P.; MACHADO, A.A.; SILVEIRA Jr., P. Sistema de análise estatística para microcomputadores: SANEST. Pelotas: UFPel, 1984. (Disquete). 